\title{
Effect of transient processes on the switching stability of dc machines
}

\author{
Viktor Kharlamov ${ }^{1, *}$, Pavel Shkodun ${ }^{1}$, and Andrey Ognevsky ${ }^{1}$ \\ ${ }^{1}$ Omsk State Transport University, 644046, Marx av., 35, Omsk, Russia
}

\begin{abstract}
Effective use of fuel and energy resources is one of the main tasks in modern industry and transport. The main directions of increasing the energy efficiency of the electric rolling stock of railways are considered in the paper. For the electric rolling stock of railways, a significant proportion of electric power consumption falls on traction needs. The consumption of electrical energy and its recovery directly depends on the proper operation and fine-tuning of the magnetic system and switching of traction electric motors of the rolling stock. The methods of testing traction electric motors currently used in railway transport do not fully correspond to their operating modes during operation. For more reliable control of their condition, a methodology for estimating the nature of the operation of traction electric motors in conditions close to real ones was proposed. Studies of the influence of transient processes on the quality of switching of traction electric motors taking into account operating conditions are carried out. Based on the results of the study, the analysis of the data obtained is carried out, and a criterion for estimating the switching stability of traction electric motors in transient operation modes is proposed. The proposed criterion allows carrying out quality control of the tuning of the magnetic system and switching of the traction electric motor, and also estimating the nature of its operation in various modes, taking into account the operating conditions.
\end{abstract}

\section{Introduction}

Nowadays, the problem of increasing the energy efficiency of the electric rolling stock is of current interest in railway transport. The criterion for the assessment of efficiency of its operation is the specific electric power consumption, which directly depends on the total consumption of electric power consumed by the electric rolling stock (ERS) [1]. The main direction of reducing the total electric power consumption according to the strategy of JSC "Russian Railways" is to increase the level of recovered energy and the efficiency of its use [2]. In addition, energy-efficient train schedules are used, which ensure a minimum specific power consumption $[3,4]$.

For ERS, the main consumers of electric power are traction electric motors (TEM) [5]. Electric power consumption for non-traction needs is about $10-20 \%$ of the total electric power consumption [6]. Accordingly, about $80-90 \%$ of the electric power from the contact

\footnotetext{
* Corresponding author: hvv-omgups@mail.ru
} 
network is converted into mechanical energy of the translational motion of the train in the traction mode. Therefore, the operation modes and tuning of the magnetic system of TEM have a significant effect on the electric power consumption. The main way to reduce electric power consumption is the use of regenerative braking [7]. The efficiency of regenerative braking directly depends on the proper operation and correct tuning of TEM.

During technical inspection at the repair enterprise, acceptance testing is carried out to verify compliance with the established requirements [8]. Their main task is to check the efficiency of the assembled electric machine.

In the process of acceptance testing, TEMs are tested in a stationary mode [9], which does not fully correspond to the conditions of their operation and does not allow monitoring the tuning of the magnetic system of TEM. To reduce the possibility of putting faulty TEMs in operation, as well as to control the tuning of the machine, it is necessary to monitor their operability not only in stationary but also in transient operating modes, and also under increased load [10].

\section{Materials and methods}

Traction motors operate in two types of transient modes: 1) a transient process with a load change; 2) a transient process when switching position on the driver's controller.

To solve the problem of controlling the tuning of the magnetic system of TEM, a test unit was created, which makes it possible to implement these two types of transient process associated with the operation conditions of TEM. In laboratory conditions, a number of experiments were performed using a set of measuring equipment of the Department of "Electrical Machines and General Electrical Engineering" of Omsk State Transport University. The test unit includes: two machines of 2PB90MGUHL4 type, measuring instruments, load resistor. The structural diagram of the test unit is shown in Fig. 1.

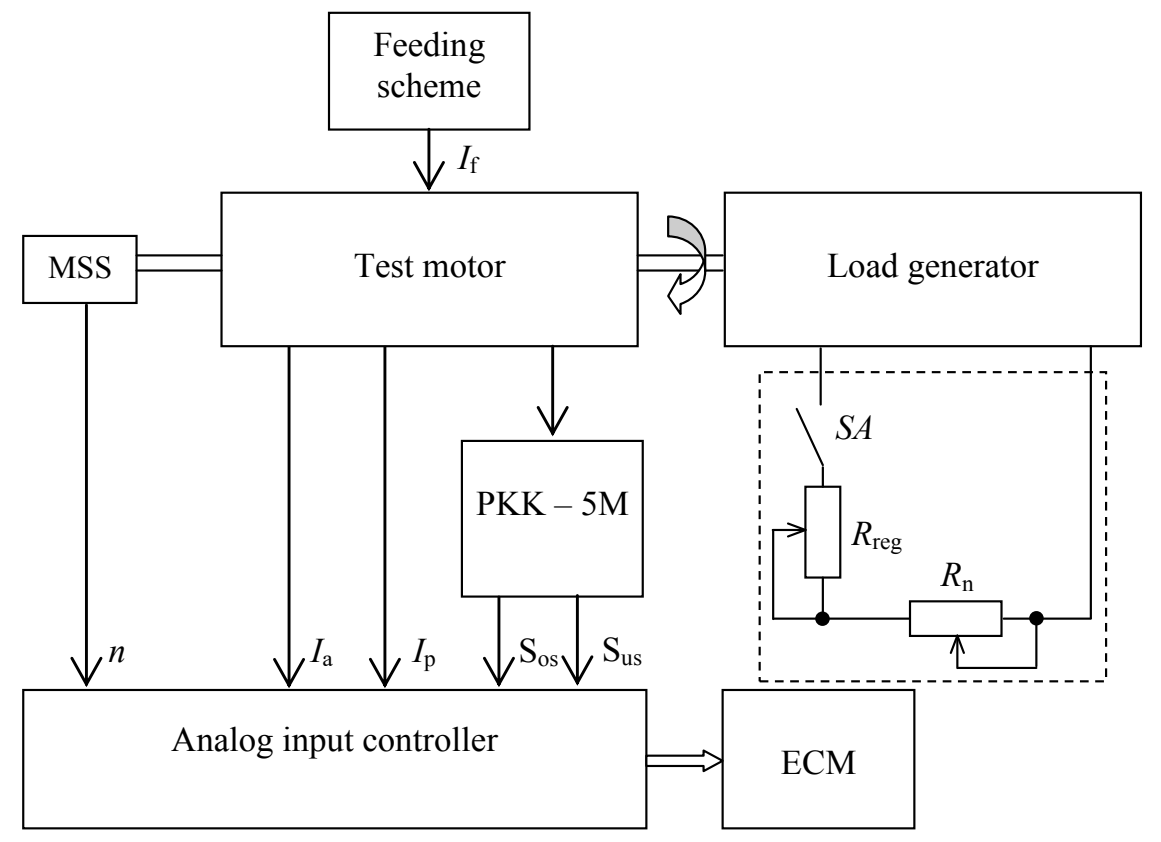

Fig. 1. Structural diagram of the test unit. 
The sparking rate from the over- and under-switched sections was monitored by the PKK5 device connected to the bipolar brushes of the machine operating in the motor mode. The motor speed $n$ was determined using a tachometer generator mounted on the shaft of the machine. Analog signals were fed to the input of the analog input controller, the output of which was connected to ECM, and with the help of specialized software, data arrays were formed [11].

The transient process of the first type is characterized by a smooth change in load and armature current without changing the applied voltage. With regard to the operating conditions of the rolling stock, such a transient process is characteristic when the track profile is changed (uphill, downhill). The transient process of the second type is characterized by a step change in the voltage applied to the motor, which leads to an armature current throw and its smooth decrease in proportion to the increase in the rotation speed of the armature. With regard to the operating conditions of the rolling stock, such a transient process occurs when switching positions on the driver's controller and removing a part of the starting resistor from the armature circuit [12-14].

In the course of the experiment, both types of transient processes were modeled. To simulate a first type of the transient process, a loading resistor of $50 \%$ and $100 \%$ of the nominal load was introduced into the armature circuit of the load generator and, after the completion of the transient process, was removed from the circuit. To simulate the transient process of the second type, a starting resistor was introduced into the armature circuit of the test motor of $50 \%$ and $100 \%$ of the resistance value of the starting resistor. At the same time, the following parameters of the test motor were recorded: feed voltage, speed of rotation, armature current, sparking rate [15]. The results of the first two experiments with the introduction and removal of the starting and loading resistor of 50\% are shown in Figures 2 and 3.

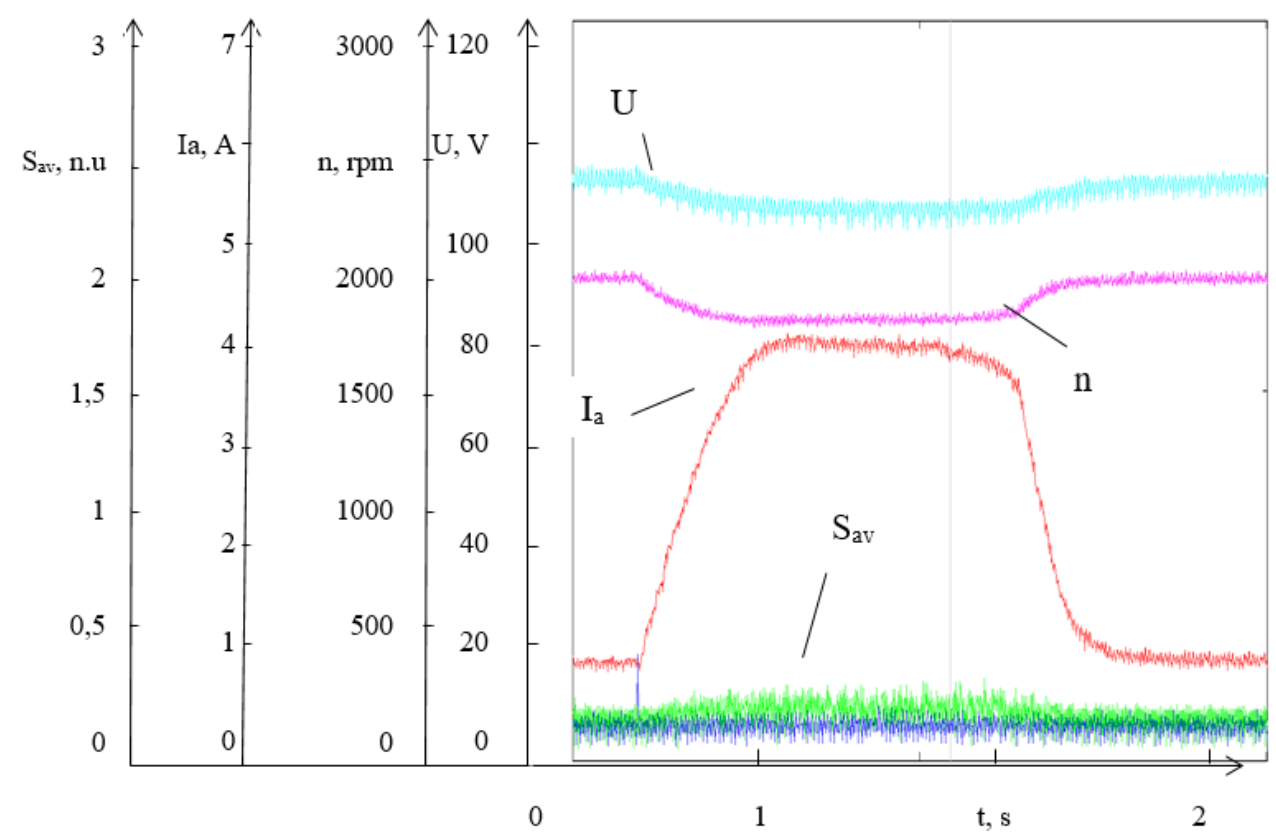

Fig. 2. The graph of the dependence of the feed voltage, the speed of rotation, the armature current, the sparking rate of the electric machine on time in the transient process of the first type. 


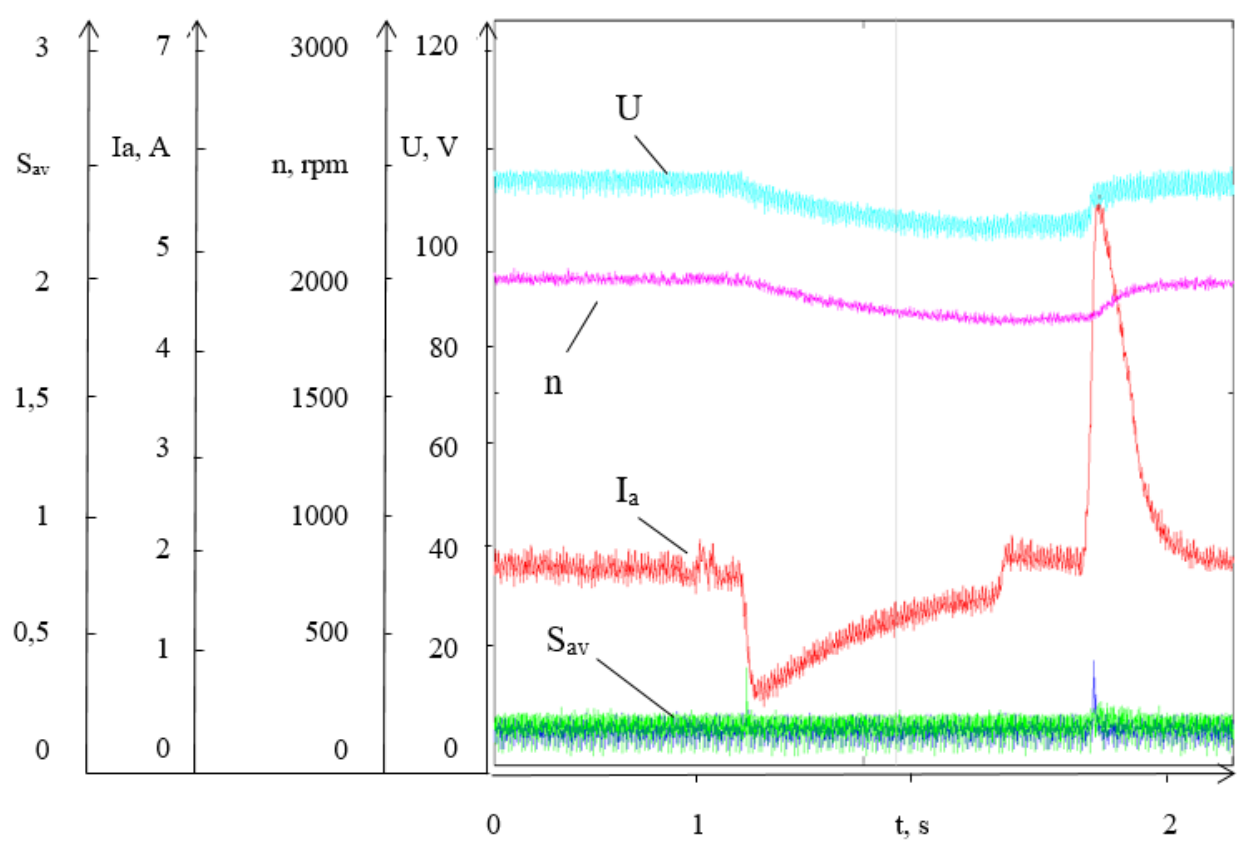

Fig. 3. The graph of the dependence of the feed voltage, the speed of rotation, the armature current, the sparking rate of the electric machine on time in the transient process of the second type.

Further, the experiments were repeated when the additional poles were feeding (or breaking) with a current of 1.6 and 2 A, respectively.

\section{Discussion}

Figure 2 shows that the sparking rate increases with increasing load. The maximum sparking rate is observed at the maximum value of the armature current. After the load is removed, the armature current is reduced to the initial value, and the sparking rate is reduced.

Figure 3 shows that a sharp decrease and increase in voltage by introducing and removing a part of the starting resistor from the armature circuit is accompanied by the inrush current. This increases the sparking rate.

It follows from the foregoing that during the transient process of the first type, the sparking rate has a function of the form:

$$
\mathrm{S}^{\sim}=\mathrm{f}\left( \pm \frac{\mathrm{dI}}{\mathrm{dt}}\right)
$$

during the transient process of the second type:

$$
\mathrm{S}^{\sim}=\mathrm{f}\left( \pm \frac{\mathrm{dI}}{\mathrm{dt}} ; \pm \Delta \mathrm{U}\right)
$$

To solve the problem of controlling the switching stability of a machine, the following criterion is proposed:

$$
\mathrm{K}=\frac{\mathrm{S}_{2}-\mathrm{S}_{1}}{\mathrm{~S}_{1}}
$$

where $\mathrm{S}_{1}$ - average sparking rate before the beginning of the transient process;

$\mathrm{S}_{2}$ - average sparking rate during the transient process. 
If $\mathrm{K} \approx 0$ means that the sparking rate of the machine does not depend on transient processes, otherwise, depending on the value of this criterion, we can make a conclusion on the degree of switching stability in transient processes. With a positive value of the criterion, it can be concluded that the transient process increases the sparking rate in the over-switched sections, with a negative value - in the under-switched sections. The degree of influence of the transient process on the switching state of the machine depends on the value of the criterion.

Let's calculate the values of this criterion for the data obtained during the experiment. For the transient process of the first type, when the voltage is relived for an average sparking rate in the over-switched and under-switched sections, respectively:

$$
\begin{gathered}
\mathrm{K}_{\mathrm{os}}=\frac{6,171-7,191}{7,191}=-0,142 ; \\
\mathrm{K}_{\mathrm{us}}=\frac{4,934-4,985}{4,985}=-0,01 ;
\end{gathered}
$$

with the surge:

$$
\begin{gathered}
\mathrm{K}_{\mathrm{os}}=\frac{6,591-5,605}{5,605}=0,176 ; \\
\mathrm{K}_{\mathrm{us}}=\frac{4,902-4,985}{4,985}=-0,017 .
\end{gathered}
$$

For a transient process of the second type, when the voltage is relived for an average sparking rate in the over-switched and under-switched sections, respectively:

$$
\begin{gathered}
\mathrm{K}_{\mathrm{os}}=\frac{5,177-5,288}{5,288}=-0,021 ; \\
\mathrm{K}_{\mathrm{us}}=\frac{4,923-4,889}{4,889}=0,001 ;
\end{gathered}
$$

with the surge:

$$
\begin{gathered}
\mathrm{K}_{\mathrm{os}}=\frac{5,574-5,22}{5,22}=0,068 \\
\mathrm{~K}_{\mathrm{us}}=\frac{5,134-4,907}{4,907}=0,046 .
\end{gathered}
$$

For other experiments, the calculation is carried out in a similar way. The results of the calculation are given in Table 1.

Based on the calculation, we can conclude that each of the types of the transient process affects the switching conditions. The machine under the study is more susceptible to sparking during the transient process of the second type, the greatest value of the criterion for it was 2.095 with the voltage surge; the greatest value of the criterion for the first type of transient process turned out to be lower and amounted to 0.327 with the power surge.

For this machine, feeding of the additional poles positively affects the switching conditions for load and voltage surges. The maximum value of the criterion for the transient process of both types turned out to be less: -0.024 and 0.65 for types 1 and 2, respectively. However, when the load and voltage were relieved, the maximum value of the criterion turned out to be greater: 0.453 and 6.161 versus -0.01 and 0.077 without feeding for types 1 and 2 , respectively. 
Table 1. Results of the calculation of the switching stability criterion from the results of the experiments.

\begin{tabular}{|c|c|c|c|c|c|}
\hline \multirow{2}{*}{$\mathrm{T}$} & $\begin{array}{c}\text { Type of transient process, value of } \\
\text { resistance of loading/starting } \\
\text { resistor, feeding/breaking current }\end{array}$ & \multicolumn{2}{|c|}{ Surge } & \multicolumn{2}{c|}{ Relief } \\
\cline { 5 - 6 } 1 & & $\mathrm{~K}_{\text {us }}$ & $\mathrm{K}_{\text {os }}$ & $\mathrm{K}_{\text {us }}$ \\
\hline 1 & $\begin{array}{c}\text { Type } 1,50 \% \text {, without } \\
\text { feeding/breaking }\end{array}$ & 0,176 & $-0,017$ & $-0,142$ & $-0,01$ \\
\hline 2 & $\begin{array}{c}\text { Type } 1,100 \% \text {, without } \\
\text { feeding/breaking }\end{array}$ & 0,327 & 0,054 & $-0,497$ & $-0,014$ \\
\hline 3 & $\begin{array}{c}\text { Type 2, 50\%, without } \\
\text { feeding/breaking }\end{array}$ & 0,068 & 0,046 & $-0,021$ & 0,001 \\
\hline 4 & $\begin{array}{c}\text { Type 2, 100\%, without } \\
\text { feeding/breaking }\end{array}$ & 0,217 & 2,095 & $-0,022$ & 0,077 \\
\hline 5 & Type 1, 50\%, feeding 1,6 A & $-0,024$ & $-0,552$ & 0,001 & 0,272 \\
\hline 6 & Type 1, 100\%, feeding 1,6 A & $-0,024$ & $-0,583$ & 0,001 & 0,453 \\
\hline 7 & Type 2, 50\%, feeding 1,6 A & $-0,096$ & $-0,785$ & 0,066 & 2,274 \\
\hline 8 & Type 2, 100\%, feeding 1,6 A & 0,65 & $-0,67$ & 0,168 & 6,161 \\
\hline 9 & Type 1, 50\%, breaking 2 A & $-0,52$ & 6,658 & $-0,373$ & $-0,768$ \\
\hline 10 & Type 1, 100\%, breaking 2 A & $-0,519$ & 8,993 & $-0,327$ & $-0,598$ \\
\hline 11 & Type 2, 50\%, breaking 2 A & $-0,788$ & 0,231 & 4,291 & $-0,051$ \\
\hline 12 & Type 2, 100\%, breaking 2 A & $-0,855$ & 2,534 & 6,534 & 0,835 \\
\hline
\end{tabular}

For this machine, breaking of additional poles has a drastic effect on switching conditions. The maximum value of the criterion for the 1 st type of the transient process was 8.993 for a surge. For the transient process of 2 nd type, the maximum values of the criterion turned out to be 2.534 for a surge and 6.534 for a relief of voltage. However, when the load was relived during a transient process of type 1 , the maximum value of the criterion was -0.327 , which indicates an improvement in the quality of switching in this case.

\section{Conclusions}

The results of the tests carried out on the test unit have shown that the transient processes of the first and second types have a direct effect on the switching of the machine. The sparking rate of the machine depends not only on the value of the armature current but also on the speed of its change. Further studies will reveal the degree of influence of transient processes on the switching stability of DC machines.

The proposed criterion makes it possible to estimate the nature of the machine operation in transient regimes taking into account the operating conditions. By the value of the criterion, one can estimate the propensity of the machine for the increase in the sparking rate when the level of the feeding voltage and load changes. In addition, the criterion shows the accuracy of the tuning of the machine's magnetic system and allows an analysis of the switching adjustment.

\section{Recommendations}

The criterion for switching stability can be applied to assess the tuning of the machine's switching during acceptance testing at the testing stations of service locomotive depots with the availability of appropriate equipment. This procedure will improve the energy performance of the machine, which will affect the consumed and recovered electrical energy, as well as avoid putting of faulty TEMs into operation. Accordingly, the reliability of the 
ERS will increase and the operating costs will decrease because of the down time of the locomotives for the repair due to the failure of TEM.

\section{References}

1. V.A. Gapanovich, V.D. Avilov, B.A. Arzhannikov, Energy saving in railway transport: a textbook for universities (Pub. House MISiS, Moscow, 2012)

2. The energy strategy of the holding "Russian Railways" for the period until 2015 and for the future until 2030, Decree of December 25, 2011 № 2718r. (Moscow, 2011)

3. M.A. Badazhkov, Bulletin of the Ural State University of Railway Transport, 111-119 (2017)

4. V.L. Nezevak, A.P. Shatokhin, O.V. Gateluk, Izvestiya Transsiba, 59-68 (2015)

5. A.R. Bakirov, Science and technology of transport, Emperor Nicholas II Moscow State University of Railway Engineering, Moscow, 15-19 (2007)

6. S.V. Kelbass, G.G. Prozorov, Bulletin of the Kazakh Academy of Transport and Communications named after M. Tynyshpaev, 108-114 (2016)

7. N.N. Sidorova, O.V. Tretinnikov, V.P. Feoktistov, Science and technology of transport, Emperor Nicholas II Moscow State University of Railway Engineering, 19-22 (2015)

8. V.V. Kharlamov, P.K. Shkodun, Electromechanical energy converters: Proceedings of the IV International Scientific and Technological Conference, Tomsk Polytechnic University, 33-37 (2009)

9. Russian Federation Standard GOST 2582-2013

10. A.Yu. Tetter, V.Yu. Tatter, Omsk Scientific Bulletin, Omsk State Transport University, 136 (2017)

11. V.V. Kharlamov, P.K. Shkodun, A.P. Afonin, Izvestiya Transsiba, Omsk State Transport University, 52-57 (2011)

12. Operating manual 2ES6 00.000.000 RE

13. A.A. Malygin, Electric locomotive 2ES6 (Transizdat, 2010)

14. A.I. Voldek, V.V. Popov, Electric machines. Introduction to electromechanics. DC machines and transformers: Textbook for universities (Piter, St. Petersburg, 2008)

15. V.V. Kharlamov, P.K. Shkodun, A.S. Ognevsky, Materials of the IV All-Russian scientific and technical conference with international participation, Omsk State Transport University, 217-222 (2017) 